\title{
Enhanced Photocatalytic Property of Cu Doped Sodium Niobate
}

\author{
Jianbin Xu, ${ }^{1,2}$ Feng Zhang, ${ }^{1}$ Bingyang Sun, ${ }^{1,2}$ Yingge Du, ${ }^{3}$ \\ Guoqiang $\mathrm{Li}^{1,2}$ and Weifeng Zhang ${ }^{1}$ \\ ${ }^{1}$ Henan Key Laboratory of Photovoltaic Materials, School of Physics \& Electronics, Henan University, Kaifeng 475004, China \\ ${ }^{2}$ Institute of Physics for Microsystems, School of Physics \& Electronics, Henan University, Kaifeng 475004, China \\ ${ }^{3}$ Environmental Molecular Sciences Laboratory, Pacific Northwest National Laboratory, Richland, WA 99352, USA
}

Correspondence should be addressed to Guoqiang Li; gqli1980@henu.edu.cn and Weifeng Zhang; wfzhang@henu.edu.cn

Received 21 June 2015; Revised 27 September 2015; Accepted 29 September 2015

Academic Editor: Wanjun Wang

Copyright (C) 2015 Jianbin Xu et al. This is an open access article distributed under the Creative Commons Attribution License, which permits unrestricted use, distribution, and reproduction in any medium, provided the original work is properly cited.

\begin{abstract}
We investigate the photocatalytic activity of $\mathrm{Cu}$ doped $\mathrm{NaNbO}_{3}$ powder sample prepared by the modified polymer complex method. The photocatalytic activity of hydrogen evolution from methanol aqueous solution was improved by $\mathrm{Cu} 2.6 \mathrm{at} \% \mathrm{doping}$. The photocatalytic degradation of rhodamine $\mathrm{B}(\mathrm{RhB})$ under visible light irradiation was enhanced in comparison with pristine $\mathrm{NaNbO}_{3} . \mathrm{Cu}$ introduction improved the adsorption property of $\mathrm{NaNbO}_{3}$, judging from the Fourier transform infrared spectra. Moreover, the ultraviolet light excitation in Cu doped sample would accelerate the mineralized process.
\end{abstract}

\section{Introduction}

Semiconductor photocatalysis, including solar energy conversion and environmental remediation, has attracted much attention in the past four decades [1]. Besides the prototypical photocatalyst $\mathrm{TiO}_{2}$, various semiconductors have been examined for the photocatalytic activities, such as water splitting, dye degradation, $\mathrm{CO}_{2}$ reduction, and air purification [210]. Development of photocatalysts with higher efficiency remains as one of the key goals in order to better utilize the solar energy.

Sodium niobate $\left(\mathrm{NaNbO}_{3}\right)$, with a pseudoperovskite structure, has been studied as a photocatalyst with potential applications in solar fuel production and organic pollutants removal [11-18]. Many approaches have been applied to improve its photocatalytic activity [15, 18-22]. In particular, element doping was used to extend light absorption to visible region and to improve the photocatalytic efficiency $[19,22-24]$. Nitrogen was first studied as the nonmetal dopant to achieve visible light activity for dye degradation and air purification $[22,23]$. Recently, $\mathrm{NaNbO}_{3}$ samples with $\mathrm{Ru}$ doping were successfully prepared by hydrothermal method. Their photocatalytic activities could be improved only after loading the novel metal $\mathrm{Pt}$, although the light absorption was extended to $600 \mathrm{~nm}$ [19]. La and Co codoping improved the light absorption property and enhanced the photocatalytic hydrogen evolution [24].

It has been demonstrated that doping $\mathrm{Cu}$ in oxides and sulfides can modify their electronic structures [25-31]. For example, the replacement of $\mathrm{Cu}$ for $\mathrm{Na}$ in $\mathrm{Na}_{2} \mathrm{Ta}_{4} \mathrm{O}_{11}$ can create visible light absorption due to the introduction of $\mathrm{Cu}$ $\mathrm{d}^{10}$ orbital in the top of valence band [25]. Doping $\mathrm{Cu}$ also could enhance the photocatalytic activity of oxide photocatalysts [26, 30-33]. For instance, the $\mathrm{Cu}$ doping significantly increased the photocatalytic activity of $\mathrm{K}_{2} \mathrm{Nb}_{4} \mathrm{O}_{11}$ catalyst [26]. $\mathrm{ZnO}$ nanorods with increasing $\mathrm{Cu}$ doping also exhibited the enhanced photocatalytic activity [34]. The $\mathrm{Cu}(\mathrm{II})$ doped $\mathrm{NaTaO}_{3}$ sample loaded with $0.3 \mathrm{wt} \% \mathrm{NiO}$ cocatalyst exhibited a dramatic increase of the activity in the hydrogen production reaction [27]. The $\mathrm{AgNbO}_{3}$ with trace of $\mathrm{Cu}$ modification showed an enhanced photocatalytic activity for oxygen evolution [35].

In this study, we investigated the $\mathrm{Cu}$ doped $\mathrm{NaNbO}_{3}$ systematically. $\mathrm{Cu}$ doped $\mathrm{NaNbO}_{3}$ powder samples were prepared by the modified polymer complex method. The 2.6 at $\%$ doped sample shows the highest activity for hydrogen evolution from aqueous methanol solution. The $\mathrm{Cu}$ doping dramatically changes the mechanism of rhodamine $\mathrm{B}(\mathrm{RhB})$ degradation under visible light irradiation. 


\section{Experimental}

The $\mathrm{NaNbO}_{3}$ powders were prepared by the modified polymer complex method [36]. The $10 \mathrm{~mL} \mathrm{NbCl}_{5}$ ethanol solution $(50 \mathrm{mg} / \mathrm{mL})$ was diluted with $50 \mathrm{~mL}$ ethanol. Different amounts of sodium alginate and copper acetate were added to the above solution with stirring according to the formula of $\mathrm{Cu}_{x} \mathrm{Na}_{1-2 x} \mathrm{NbO}_{3}$. The nominal $\mathrm{Cu}$ molar amounts were 0 , $0.026,0.052$, and 0.078 . Then citric acid $(10 \mathrm{~g})$ and polyethylene glycol $(10 \mathrm{~g})$ were added. The mixtures were heated at $60^{\circ} \mathrm{C}$ until they turned into solid. The obtained solids were then heated at $390^{\circ} \mathrm{C}$ for $4 \mathrm{~h}$ and at $450^{\circ} \mathrm{C}$ for $3 \mathrm{~h}$ to form the original samples. To remove the $\mathrm{Cu}$ remains on the surface, we washed all original samples with diluted hydrochloric acid until the solution is colorless. The final samples were denoted as $\mathrm{NN}, \mathrm{A}, \mathrm{B}$, and $\mathrm{C}$, respectively.

The crystal structures of samples were determined by an X-ray diffractometer (DX-2700 diffractometer, Fangyuan) with $\mathrm{Cu} \mathrm{K} \alpha$ radiation $(\lambda=0.1542 \mathrm{~nm})$. Fourier transform infrared (FTIR) spectra were measured by a spectrophotometer with $\mathrm{KBr}$ as the reference sample. Raman scattering spectra were obtained by a laser Raman spectrophotometer (RM-1000, Renishaw). The elements were analyzed by energy dispersive spectroscopy (EDS). The diffuse reflectance spectra were recorded using a UV-Uis spectrophotometer (UV2550) and transformed to the absorption spectra automatically according to the Kubelka-Munk relationship.

Photocatalytic activity was evaluated by the photocatalytic hydrogen evolution and degradation of RhB under light irradiation, which was emitted from a $300 \mathrm{~W}$ Xe lamp without filters. The sample $(0.05 \mathrm{~g})$ was added in $50 \mathrm{~mL}$ aqueous methanol solution (methanol: $20 \mathrm{vol} \%$ ) in a glass reactor. Aqueous $\mathrm{H}_{2} \mathrm{PtCl}_{6}(10 \mathrm{~g} / \mathrm{L}, 33.2 \mu \mathrm{L})$ solution was added to form a Pt cocatalyst. Before photocatalytic reaction, the reaction system was vacuumed and purged with $\mathrm{N}_{2}$ for 30 min to remove $\mathrm{O}_{2}$ that was dissolved in the aqueous solution. After being sealed by a quartz cover, the solution was irradiated from the topside by $300 \mathrm{~W}$ Xe lamp. The stirring was on during the reaction. The amount of $\mathrm{H}_{2}$ evolved was determined using gas chromatography (GC1690, Kexiao Ltd.).

The photocatalytic degradation of $\mathrm{RhB}$ was carried out with $0.01 \mathrm{~g}$ powder sample suspended in a $100 \mathrm{~mL} \mathrm{RhB}$ solution $(2.5 \mathrm{mg} / \mathrm{L})$ in a glass cell. The suspension was first allowed to reach adsorption-desorption equilibrium with continuous stirring for half an hour in the dark. The variation in $\mathrm{RhB}$ concentration was recorded using a UV-Vis spectrophotometer (UV-2550) by measuring the absorbance of the main peak.

The amount of ${ }^{\bullet} \mathrm{OH}$ radical, which is one of the important oxidization species, was measured by reported methods [37]. The reaction principle was that terephthalic acid (TA) readily reacted with ${ }^{\circ} \mathrm{OH}$ radicals to produce highly fluorescent product, 2-hydroxyterephthalic acid (TAOH), which emitted photoluminescence at around $426 \mathrm{~nm}$ on the excitation of its own $312 \mathrm{~nm}$ absorption band. The intensity of the peak attributed to $\mathrm{TAOH}$ was known to be proportional to the amount of ${ }^{\circ} \mathrm{OH}$ radicals formed. The experimental process was briefly described below. The $0.01 \mathrm{~g}$ powder sample was suspended in $100 \mathrm{~mL}$ solution $(20 \mathrm{mM} \mathrm{NaOH}$ and $6 \mathrm{mM}$ terephthalic acid). After $0.5 \mathrm{~h}$ of full arc Xe lamp irradiation, the solution was used for fluorescence spectrum measurements (Horiba, JY FluoroLog-3).

\section{Results and Discussion}

The XRD patterns of all samples are shown in Figure 1(a). All of them could be indexed as the perovskite phase of sodium niobate according to PDF\#19-1221. The crystalline quality is characterized by the full width at half maximum (FWHM) of the XRD curve. Compared with the NN sample, the FWHM of the peak located at $2 \theta=22.7^{\circ}$ in the $\mathrm{Cu}$ doped samples decreases as shown on the right of Figure 1(a), indicating that the crystalline quality becomes better due to introducing $\mathrm{Cu}$. The grain size could be estimated from the FWHM using Scherrer's equation: $d_{\mathrm{XRD}}=0.9 \lambda /(\beta * \cos (\theta))$, where $\lambda$ is the $\mathrm{X}$-ray wavelength; $\beta$ is the FWHM (in radian); and $\theta$ is the half of diffraction peak angle $(2 \theta)$. The grain sizes were estimated to be $13 \mathrm{~nm}$ for $\mathrm{NN}$ and $22 \mathrm{~nm}$ for $\mathrm{Cu}$ doped samples, which was similar to the samples prepared by the polymer complex method [36]. When the Cu substituted for $\mathrm{Na}$ below $80 \%$ in $\mathrm{Na}_{2} \mathrm{Nb}_{4} \mathrm{O}_{11}$, the lattice constant would increase [25]. However, in our case, no peak shift was found due to the smaller concentration of $\mathrm{Cu}$. The element analysis results for $\mathrm{Cu} / \mathrm{Nb}$ ratios in the samples are in good agreement with the nominal values, as shown in Figure 1(b). Moreover, the main valence state of $\mathrm{Cu}$ is +1 , judging from the result of X-ray photoelectron spectra (XPS), as shown in Figure 1(c). We, therefore, consider the $\mathrm{Cu}$ doped into the lattice as our expectation.

To identify the change of structure due to $\mathrm{Cu}$ introduction, Raman and FTIR spectroscopy were measured, as shown in Figure 2. The Raman spectra indicated that the $\mathrm{Cu}$ introduction did not change the $\mathrm{NbO}_{6}$ bonding length. As a comparison, when part of $\mathrm{Na}$ was replaced by $\mathrm{Ag}$, the Raman band at $\sim 600 \mathrm{~cm}^{-1}$ corresponding to the stretching model of $\mathrm{NbO}_{6}$ octahedron was shifted to higher wavenumber [38]. In FTIR spectra, the peak at $1063 \mathrm{~cm}^{-1}$ was associated with the bending modes of the adsorbed water [39]. Zhong et al. found that the $\mathrm{Cu}-\mathrm{O}_{\text {ads }}-(\mathrm{CO})_{\text {ads }}$ will generate a IR band above $1080 \mathrm{~cm}^{-1}$ [40]. Therefore, we assigned the peak at $1088 \mathrm{~cm}^{-1}$ as the result of $\mathrm{Cu}$ doping, representing the adsorption property of the surface. For easy comparison, we normalized the intensity of $1088 \mathrm{~cm}^{-1}$ to $1063 \mathrm{~cm}^{-1}$. The result indicated that the $\mathrm{Cu}$ doping changed the ratio of the intensity of peak at 1088 and $1063 \mathrm{~cm}^{-1}$, as shown in the inset of Figure 2(b). Sample A has the largest value, implying the best adsorption properties. For further increasing the $\mathrm{Cu}$ content, the ratio decreased, indicating that the $\mathrm{Cu}$ doping has an optimum amount. When the content of $\mathrm{Cu}$ is over the optimum amount, the $\mathrm{Cu}$ will aggregate on the surface and possibly screen the IR signal. Furthermore, it is known that the shape of the intense band at $\sim 670 \mathrm{~cm}^{-1}$ corresponds to an asymmetric enlargement of the $\mathrm{Nb}-\mathrm{O}$ bond of the octahedral $\mathrm{NbO}_{6}$ structures [22]. No change of that band among those samples revealed that the $\mathrm{Nb}-\mathrm{O}$ band length did not change, which is consistent with the Raman results. 


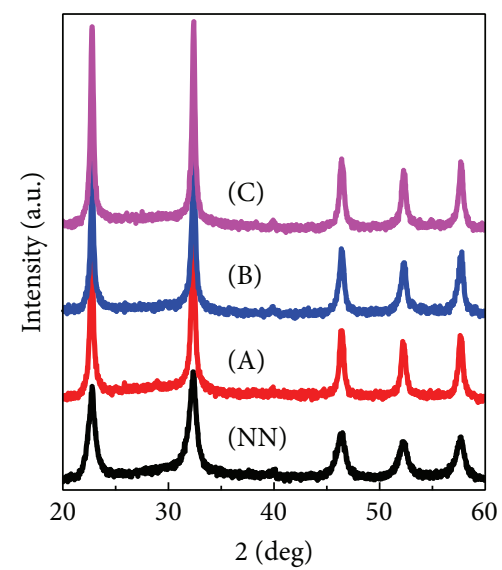

(a)
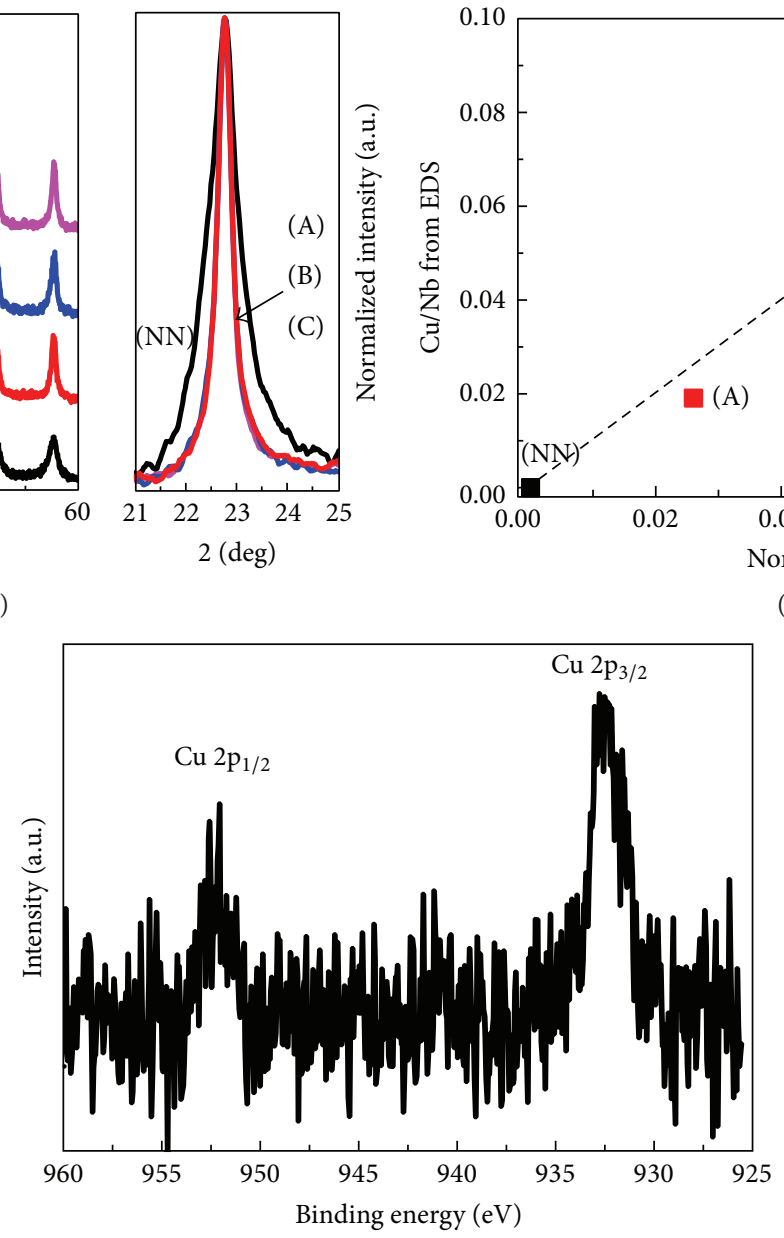

(c)

Figure 1: (a) X-ray diffraction patterns of NN, A, B, and C (left). Enlarged view of the main peak at 22.7 (right). (b) Cu/Nb ratio obtained from EDS analysis (black squares). The dash line represents the theoretical value. (c) $\mathrm{Cu} 2 \mathrm{p}$ line obtained from $\mathrm{B}$.

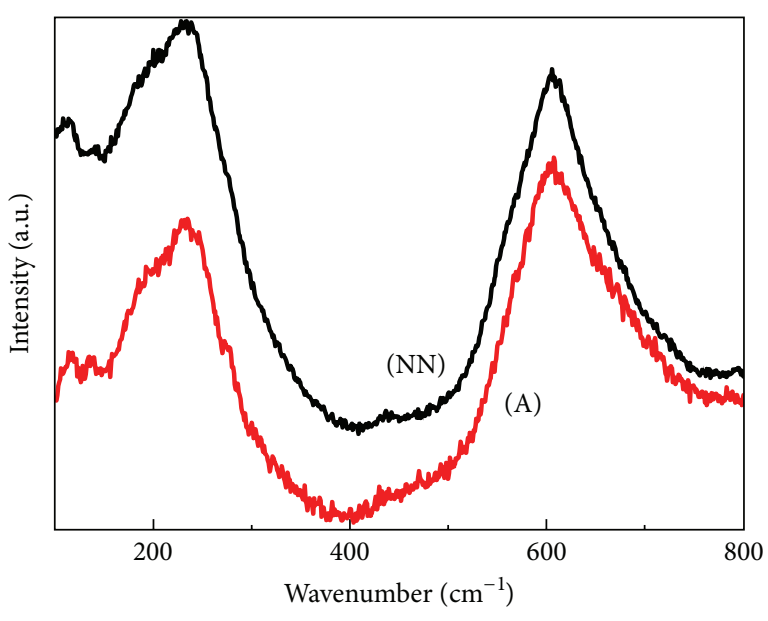

(a)

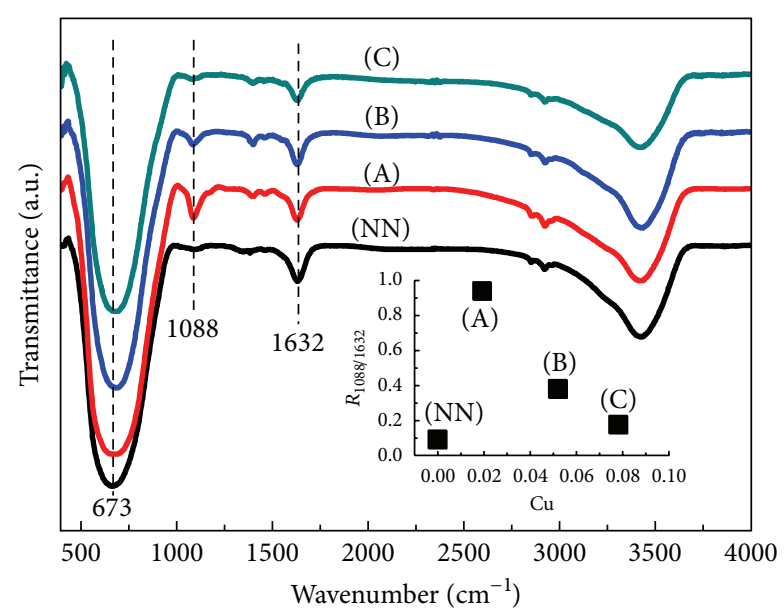

(b)

Figure 2: (a) Raman and (b) FTIR spectra of NN, A, B, and C. The inset in (b) is the normalized intensity of peak at 1088 to $1632 \mathrm{~cm}^{-1}$ as a function of $\mathrm{Cu}$ content. 


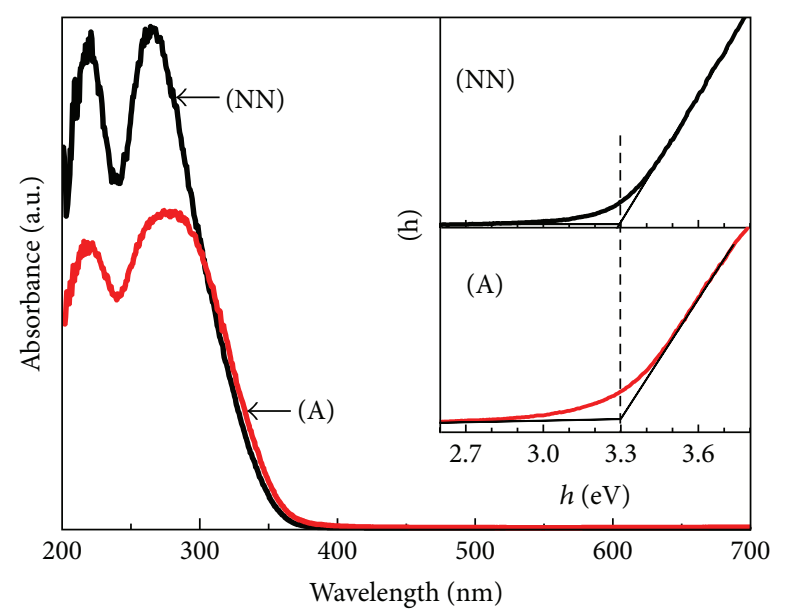

FIGURE 3: Diffuse reflectance spectra of NN and A. The insets are the plots used to estimate the band gap.

Diffuse reflectance spectra of $\mathrm{NN}$ and A are shown in Figure 3. The absorption edges are very similar, indicating that the $\mathrm{Cu}$ doping do not change the light absorption edge. Palasyuk et al. reported that $1 \% \mathrm{Cu}$ doping would change the light absorption of $\mathrm{Na}_{2} \mathrm{Ta}_{4} \mathrm{O}_{11}$ significantly [25]. However, no obvious shift was observed in our case. Actually, the other $\mathrm{Cu}$ doped samples showed very similar absorption spectra with that of NN. The optical band gaps could be estimated from the absorption spectra using the following equation: $(\alpha h v)=M\left(h v-E_{g}\right)^{n / 2}$, where $M, \alpha, h v$, and $E_{g}$ are constant, absorption coefficient, the photon energy, and the optical band gap, respectively. In this equation, $n$ is determined by the transition type and is equal to 1 for direct transition and 4 for indirect one. The values of $n$ and $E_{g}$ were estimated by the following steps: first, the plot of $\ln (\alpha h v)$ versus $\ln \left(h v-E_{g}\right)$ was drawn using an approximate value of $E_{g}$, and then the value of $n$ was estimated from the slope of the straight line near the band edge; second, the plot of $(\alpha h v)^{2 / n}$ versus $h v$ was drawn and then a tangential line was plotted near the band edge; the $x$-intercept of the tangential line corresponded to the optical band gap. The $n$ for NN is equal to 4 because of the indirect transition. The band gaps of $\mathrm{NN}$ and $\mathrm{A}$ are the same and are estimated to be $3.3 \mathrm{eV}$, which is slightly smaller than $3.4 \mathrm{eV}$ obtained from samples prepared by solid state reaction method and larger than $3.0 \mathrm{eV}$ obtained from the plate like $\mathrm{NaNbO}_{3}[41,42]$.

These samples were tested for $\mathrm{H}_{2}$ evolution from aqueous methanol solution, as displayed in Figure $4 . \mathrm{H}_{2}$ could be generated for all four samples. While sample A (2.6 at $\%$ $\mathrm{Cu}$ doping) shows the highest activity, the amount of $\mathrm{H}_{2}$ evolution increased in the order of $\mathrm{C}<\mathrm{B}<\mathrm{NN}<\mathrm{A}$. The $\mathrm{H}_{2}$ evolution rate was $112 \mu \mathrm{mol} / \mathrm{h}$ for C, $214 \mu \mathrm{mol} / \mathrm{h}$ for $\mathrm{B}$, $228 \mu \mathrm{mol} / \mathrm{h}$ for $\mathrm{NN}$, and $343 \mu \mathrm{mol} / \mathrm{h}$ for A. These results are larger than the samples prepared by solid state reaction under different atmospheres [43]. The suitable amount of $\mathrm{Cu}$ doping could enhance the photocatalytic $\mathrm{H}_{2}$ evolution. In previous report amorphous $\mathrm{Cu}(\mathrm{II})$ clusters modified $\alpha-\mathrm{Bi}_{2} \mathrm{O}_{3}$ exhibited an enhanced photocatalytic activity [32]. Consequently,

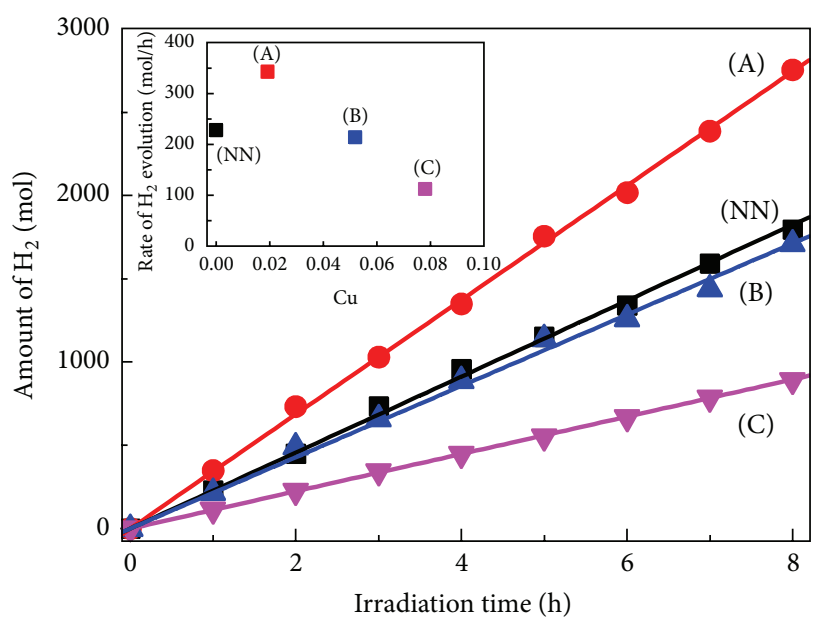

Figure 4: Amount of $\mathrm{H}_{2}$ evolution from aqueous methanol solution varied with irradiation time over NN, A, B, and C. The inset is the plot of rate of $\mathrm{H}_{2}$ evolution.

we consider the enhanced activity of $\mathrm{H}_{2}$ evolution originated from the better crystallinity and adsorption property.

Photocatalytic activity for the decomposition of $\mathrm{RhB}$ in an aqueous solution was evaluated in the presence of samples under visible light irradiation of Xe lamp. The variation in the concentration of $\mathrm{RhB}$ was recorded by measuring the UVVis spectrum. These temporal UV-visible spectral changes of $\mathrm{RhB}$ aqueous solution over $\mathrm{NN}$ and A during the photocatalytic degradation reactions are shown in Figure 5(a). In the presence of $\mathrm{A}, \mathrm{RhB}$ underwent pronounced photocatalytic degradation upon visible light irradiation. The wavelength corresponding to the maximal absorbance $\left(\lambda_{\max }\right)$ shifts gradually from the initial $554 \mathrm{~nm}$ towards shorter wavelength and finally reaches $498 \mathrm{~nm}$, along with a gradual decrease in the maximal absorbance during photocatalytic reactions of the $\mathrm{RhB}$ solution, which are further quantitatively demonstrated in Figure 5(b). However, in case of NN, only a very small 


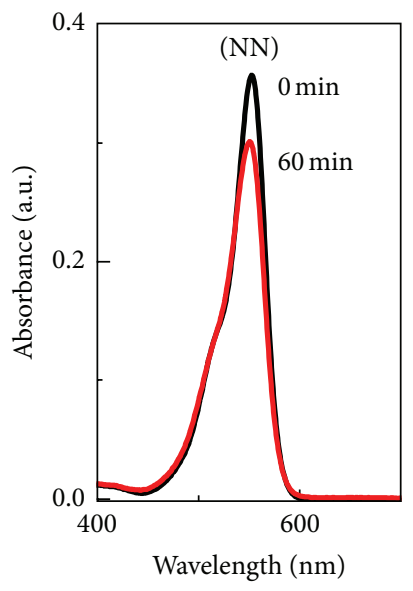

(a)

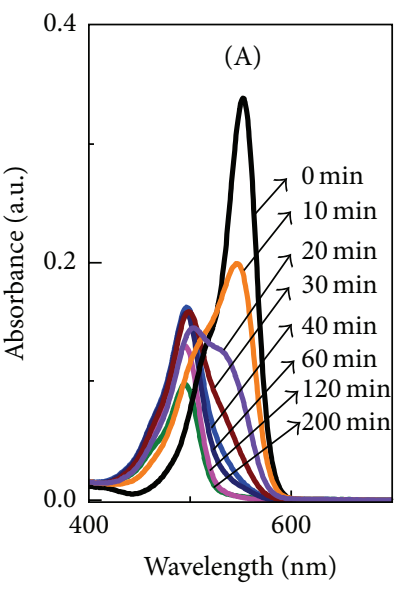

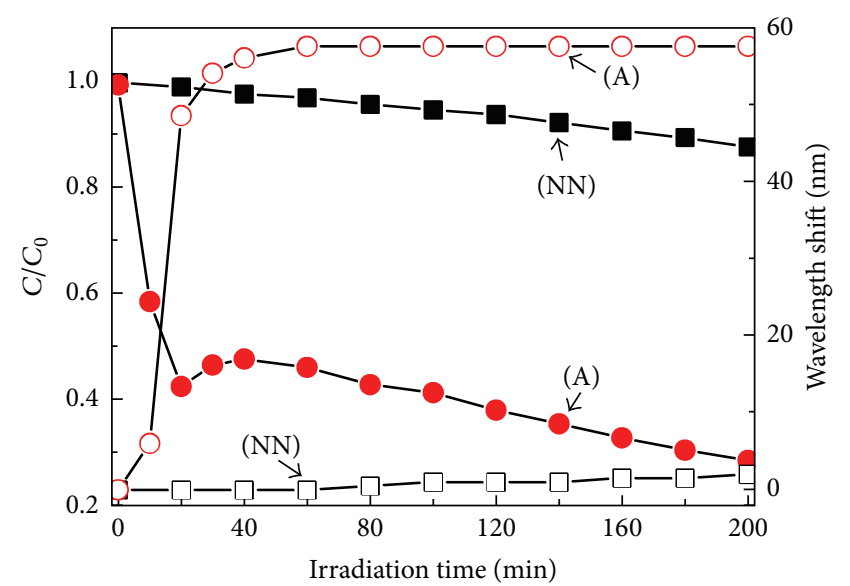

(b)

Figure 5: (a) Temporal changes of RhB absorption spectra in presence of NN and A under visible light irradiation $(\lambda>420 \mathrm{~nm})$. (b) Variation in $C / C_{0}$ (solid square and spot) and wavelength shift (empty square and cycle) over $\mathrm{NN}$ and $\mathrm{A}$ under visible light irradiation.

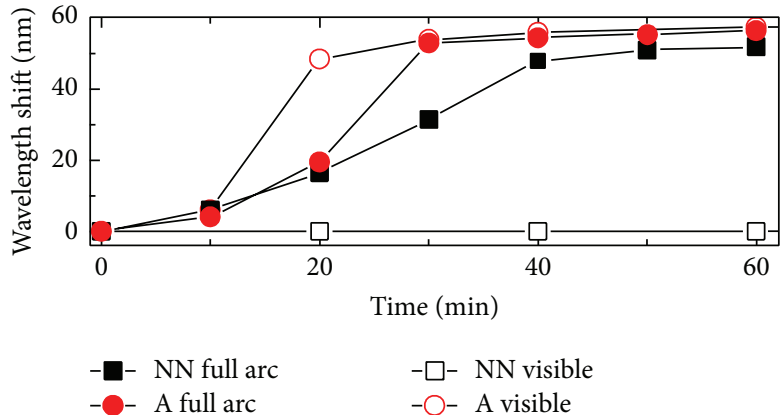

(a)

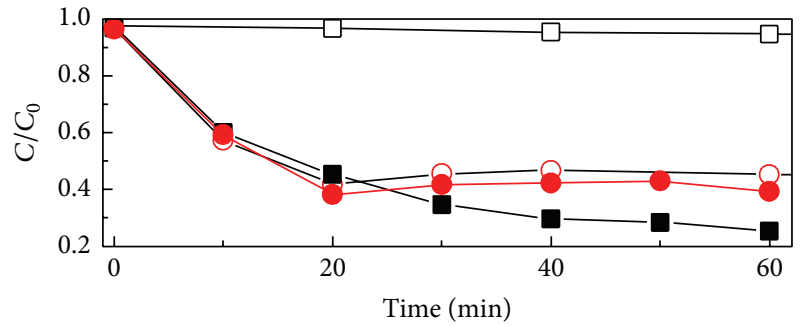

NN full arc A full arc

$$
-\square-\mathrm{NN} \text { visible }
$$

(b)

Figure 6: Variation in $C / C_{0}$ (b) and wavelength shift (a) over NN and A under full arc Xe lamp irradiation (solid square and cycle). Those under visible light (empty square and cycle) were also shown for comparison.

decrease in absorbance was observed and almost no shift of $\lambda_{\text {max }}$. Neither NN nor A can absorb the visible light. Therefore, the RhB decomposition over A is mainly considered as RhB sensitive self-degradation. From the FTIR we can find that the $\mathrm{Cu}$ doping improved the adsorption property. The $\mathrm{RhB}$ sensitive self-degradation is very close to the adsorption $[44,45]$. Accordingly, we conclude that $\mathrm{Cu}$ doping enhanced the adsorption of $\mathrm{RhB}$, leading to an improved photocatalytic activity.

We also carried out the experiment under full arc irradiation of Xe lamp. Both NN and A show the similar spectra profiles, as demonstrated in Figure 6. Sample A exhibits similar activity under visible light and full arc irradiation. The blue shift of $\lambda_{\max }$ frequently observed in oxidizing $\mathrm{RhB}$ using oxides as photocatalyst is associated with the stepwise removal of the $\mathrm{N}$-ethyl group during degradation of $\mathrm{RhB}$ (i.e., $\mathrm{N}, \mathrm{N}, \mathrm{N}^{\prime}, \mathrm{N}^{\prime}$-tetra-ethylated rhodamine) molecule [46, 47]. NN shows significantly different behaviors under full arc irradiation from that under visible light irradiation. $\mathrm{NN}$ could be excited by the UV light. Therefore, the removal of the $\mathrm{N}$-ethyl group under full arc irradiation was thought to be caused by the light absorption.
We expected that the $\mathrm{RhB}$ degradation was related to the ${ }^{\circ} \mathrm{OH}$ radical. To confirm that ${ }^{\circ} \mathrm{OH}$ had effect on the dye degradation, we employed photoluminescence spectroscopy using terephthalic acid to test ${ }^{\circ} \mathrm{OH}$, as shown in Figure 7 $[37,46,48]$. We observed significant emission signal at $425 \mathrm{~nm}$ for NN and A sample after full arc irradiation for $0.5 \mathrm{~h}$, confirming that significant ${ }^{\circ} \mathrm{OH}$ radical was produced during the light irradiation and that it was involved in the photodegradation reaction. Moreover, when the isopropanol was added in the system, no degradation was found under full arc and visible light irradiation. These results indicated that the ${ }^{\bullet} \mathrm{OH}$ is mainly the oxidized species [49]. The very small emission signal under visible light irradiation could be caused by the leakage of UV light through the filter.

In the liquid phase, ${ }^{\circ} \mathrm{OH}$ could be generated by the photogenerated electrons and holes $[1,50]$. Methanol, which is usually used as sacrificing agent in the hydrogen evolution from water, could react with the photogenerated hole [2, $49,51]$. When the methanol was added in the solution, the processes of the $\mathrm{N}$-ethyl group removal both under irradiation were delayed, as shown in Figure 8. This fact implied that the hole took part in the reaction. Moreover, 


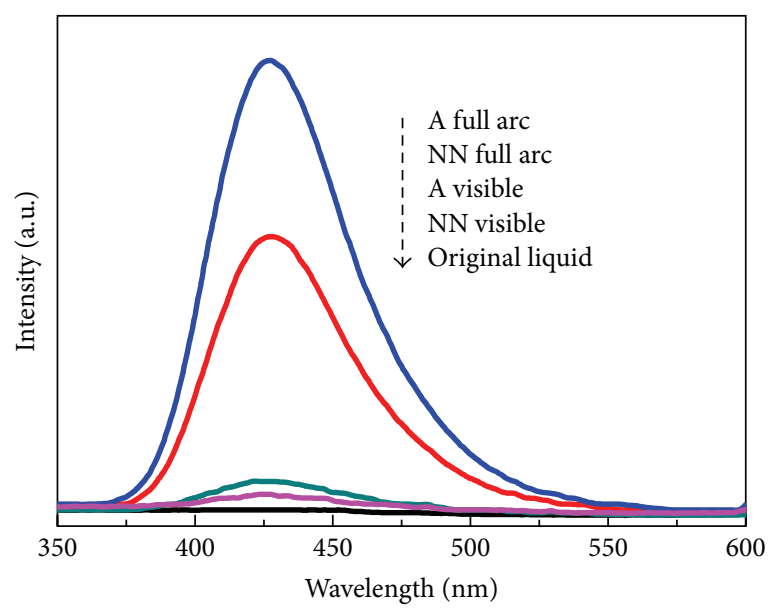

Figure 7: Fluorescence spectra of 2-hydroxyterephthalic acid (TAOH) over NN and A after $1 \mathrm{~h}$ of full arc and visible light irradiation of Xe lamp.

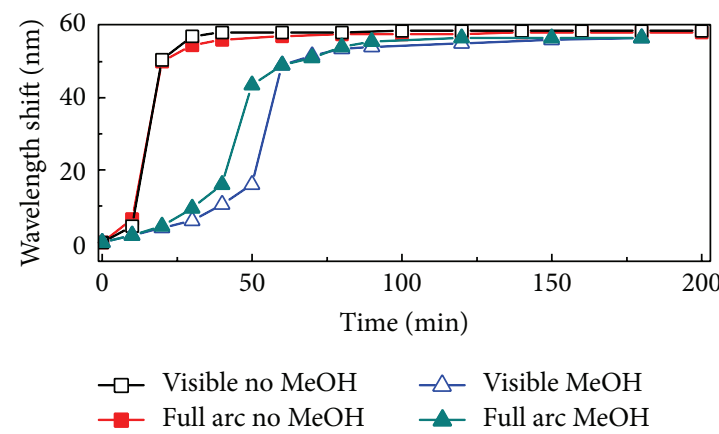

(a)

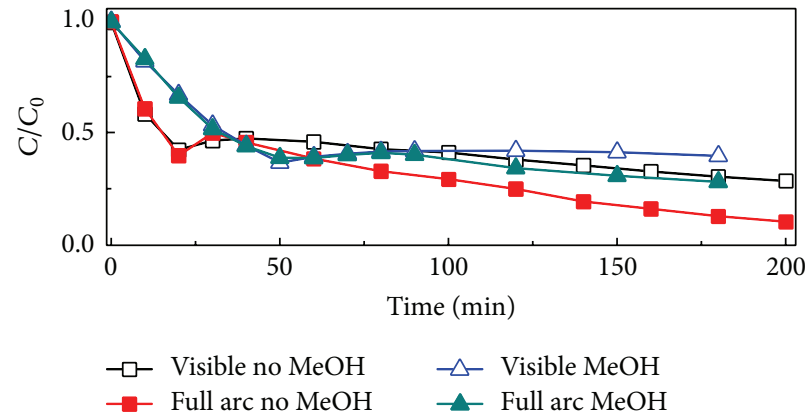

(b)

Figure 8: Variation in $C / C_{0}$ (b) and wavelength shift (a) over A with and without methanol under full arc and visible light irradiation of Xe lamp.

when the system was irradiated by the full arc of Xe lamp, the process of mineralization will be speeded up in both reactions with and without methanol. These results indicated that the excitation of ultraviolet light in $\mathrm{Cu}$ doped sample only impacts the mineralized process.

\section{Conclusions}

The nominal $\mathrm{Cu}$ atoms were doped into the sample. No changes of crystal structure and optical band gap were observed in $\mathrm{Cu}$ doped samples. Doping $\mathrm{Cu}$ improved the adsorption property. The photocatalytic activity of hydrogen evolution was improved by $\mathrm{Cu} 2.6$ at $\%$ doping. The photocatalytic degradation of $\mathrm{RhB}$ under visible light was enhanced in comparison with the pristine $\mathrm{NaNbO}_{3}$. Moreover, the photoexcitation in $\mathrm{Cu}$ doped sample only impacts the process of mineralization.

\section{Conflict of Interests}

The authors declare that there is no conflict of interests regarding the publication of this paper.

\section{Acknowledgments}

This work was supported by the National Natural Science Foundation of China (21103041 and 51402088) and 863 Program of China (2015AA034201).

\section{References}

[1] H. Kisch, "Semiconductor photocatalysis-mechanistic and synthetic aspects," Angewandte Chemie: International Edition, vol. 52, no. 3, pp. 812-847, 2013.

[2] F. E. Osterloh, "Inorganic nanostructures for photoelectrochemical and photocatalytic water splitting," Chemical Society Reviews, vol. 42, no. 6, pp. 2294-2320, 2013.

[3] Y. Zhang, T. Mori, and J. Ye, "Polymeric carbon nitrides: semiconducting properties and emerging applications in photocatalysis and photoelectrochemical energy conversion," Science of Advanced Materials, vol. 4, no. 2, pp. 282-291, 2012.

[4] Z. Zou, J. Ye, K. Sayama, and H. Arakawa, "Direct splitting of water under visible light irradiation with an oxide semiconductor photocatalyst," Nature, vol. 414, no. 6864, pp. 625-627, 2001.

[5] K. Maeda, K. Teramura, D. Lu et al., "Photocatalyst releasing hydrogen from water," Nature, vol. 440, article 295, 2006. 
[6] X. Wang, Q. Xu, M. R. Li et al., "Photocatalytic overall water splitting promoted by an $\alpha-\beta$ phase junction on $\mathrm{Ga}_{2} \mathrm{O}_{3}$," Angewandte Chemie International Edition, vol. 51, pp. 1308913092, 2012.

[7] X. C. Wang, K. Maeda, A. Thomas et al., "A metal-free polymeric photocatalyst for hydrogen production from water under visible light," Nature Materials, vol. 8, no. 1, pp. 76-80, 2009.

[8] Z. G. Yi, J. H. Ye, N. Kikugawa et al., "An orthophosphate semiconductor with photooxidation properties under visiblelight irradiation," Nature Materials, vol. 9, no. 7, pp. 559-564, 2010.

[9] G. Liu, J. C. Yu, G. Q. Lu, and H.-M. Cheng, "Crystal facet engineering of semiconductor photocatalysts: motivations, advances and unique properties," Chemical Communications, vol. 47, no. 24, pp. 6763-6783, 2011.

[10] K. Hashimoto, H. Irie, and A. Fujishima, " $\mathrm{TiO}_{2}$ photocatalysis: a historical overview and future prospects," Japanese Journal of Applied Physics, vol. 44, no. 12, pp. 8269-8285, 2005.

[11] B. Zielińska, J. Sreńscek-Nazzal, and R. J. Kaleńczuk, "Photocatalytic hydrogen generation over alkali niobates in the presence of organic compounds," Polish Journal of Chemical Technology, vol. 10 , no. 4, pp. 1-3, 2008.

[12] K.-I. Katsumata, C. E. J. Cordonier, T. Shichi, and A. Fujishima, "Photocatalytic activity of $\mathrm{NaNbO}_{3}$ thin films," Journal of the American Chemical Society, vol. 131, no. 11, pp. 3856-3857, 2009.

[13] K. Saito and A. Kudo, "Niobium-complex-based syntheses of sodium niobate nanowires possessing superior photocatalytic properties," Inorganic Chemistry, vol. 49, no. 5, pp. 2017-2019, 2010.

[14] C. Shifu, J. Lei, T. Wenming, and F. Xianliang, "Fabrication, characterization and mechanism of a novel Z-scheme photocatalyst $\mathrm{NaNbO}_{3} / \mathrm{WO}_{3}$ with enhanced photocatalytic activity," Dalton Transactions, vol. 42, no. 30, pp. 10759-10768, 2013.

[15] X. K. Li, Q. Li, and L. Y. Wang, "The effects of $\mathrm{NaNbO}_{3}$ particle size on the photocatalytic activity for 2-propanol photodegradation," Physical Chemistry Chemical Physics, vol. 15, no. 34, pp. 14282-14289, 2013.

[16] L. Q. Jiang, Y. H. Zhang, Y. Qiu, and Z. G. Yi, "Improved photocatalytic activity by utilizing the internal electric field of polar semiconductors: a case study of self-assembled $\mathrm{NaNbO}_{3}$ oriented nanostructures," RSC Advances, vol. 4, no. 7, pp. 31653170, 2014.

[17] P. Li, H. Xu, L. Q. Liu et al., "Constructing cubic-orthorhombic surface-phase junctions of $\mathrm{NaNbO}_{3}$ towards significant enhancement of $\mathrm{CO}_{2}$ photoreduction," Journal of Materials Chemistry A, vol. 2, no. 16, pp. 5606-5609, 2014.

[18] H. Shi, G. Chen, and Z. Zou, "Platinum loaded $\mathrm{NaNbO}_{3-x} \mathrm{~N}_{x}$ with nanostep surface nanostructures toward enhanced visiblelight photocatalytic activity," Applied Catalysis B: Environmental, vol. 156-157, pp. 378-384, 2014.

[19] B. Paul and K.-H. Choo, "Visible light active Ru-doped sodium niobate pervoskite decorated with platinum nanoparticles via surface capping," Catalysis Today, vol. 230, pp. 138-144, 2014.

[20] S. Kumar, S. Khanchandani, M. Thirumal, and A. K. Ganguli, "Achieving enhanced visible-light-driven photocatalysis using type-II $\mathrm{NaNbO}_{3} / \mathrm{CdS}$ core/shell heterostructures," ACS Applied Materials and Interfaces, vol. 6, no. 15, pp. 13221-13233, 2014.

[21] S. F. Chen, Y. F. Hu, L. Ji, X. L. Jiang, and X. L. Fu, "Preparation and characterization of direct $\mathrm{Z}$-scheme photocatalyst $\mathrm{Bi}_{2} \mathrm{O}_{3} / \mathrm{NaNbO}_{3}$ and its reaction mechanism," Applied Surface Science, vol. 292, pp. 357-366, 2014.
[22] G. Q. Li, N. Yang, W. L. Wang, and W. F. Zhang, "Synthesis, photophysical and photocatalytic properties of N-doped sodium niobate sensitized by carbon nitride," Journal of Physical Chemistry C, vol. 113, no. 33, pp. 14829-14833, 2009.

[23] H. F. Shi, X. K. Li, H. Iwai, Z. G. Zou, and J. H. Ye, "2-propanol photodegradation over nitrogen-doped $\mathrm{NaNbO}_{3}$ powders under visible-light irradiation," Journal of Physics and Chemistry of Solids, vol. 70, no. 6, pp. 931-935, 2009.

[24] P. Li, H. Abe, and J. Ye, "Band-gap engineering of $\mathrm{NaNbO}_{3}$ for photocatalytic $\mathrm{H}_{2}$ evolution with visible light," International Journal of Photoenergy, vol. 2014, Article ID 380421, 6 pages, 2014.

[25] O. Palasyuk, A. Palasyuk, and P. A. Maggard, "Site-differentiated solid solution in $\left(\mathrm{Na}_{1-x} \mathrm{Cu}_{x}\right)_{2} \mathrm{Ta}_{4} \mathrm{O}_{11}$ and its electronic structure and optical properties," Inorganic Chemistry, vol. 49, no. 22, pp. 10571-10578, 2010.

[26] G. K. Zhang, X. Zou, J. Gong et al., "Characterization and photocatalytic activity of $\mathrm{Cu}$-doped $\mathrm{K}_{2} \mathrm{Nb}_{4} \mathrm{O}_{11}$," Journal of Molecular Catalysis A: Chemical, vol. 255, no. 1-2, pp. 109-116, 2006.

[27] L. Xu, C. Li, W. Shi, J. Guan, and Z. Sun, "Visible light-response $\mathrm{NaTa}_{1-x} \mathrm{Cu}_{x} \mathrm{O}_{3}$ photocatalysts for hydrogen production from methanol aqueous solution," Journal of Molecular Catalysis A: Chemical, vol. 360, pp. 42-47, 2012.

[28] S. H. Shen, L. Zhao, Z. H. Zhou, and L. J. Guo, "Enhanced photocatalytic hydrogen evolution over $\mathrm{Cu}$-doped $\mathrm{ZnIn}_{2} \mathrm{~S}_{4}$ under visible light irradiation," Journal of Physical Chemistry $C$, vol. 112, no. 41, pp. 16148-16155, 2008.

[29] A. Manikandan, J. Judith Vijaya, L. John Kennedy, and M. Bououdina, "Structural, optical and magnetic properties of $\mathrm{Zn}_{1-\mathrm{x}} \mathrm{Cu}_{\mathrm{x}} \mathrm{Fe}_{2} \mathrm{O}_{4}$ nanoparticles prepared by microwave combustion method," Journal of Molecular Structure, vol. 1035, pp. 332340, 2013.

[30] Z. H. Li, H. Dong, Y. F. Zhang et al., "Effect of $\mathrm{M}^{2+}(\mathrm{M}=\mathrm{Zn}$ and $\mathrm{Cu}$ ) dopants on the electronic structure and photocatalytic activity of $\operatorname{In}(\mathrm{OH})_{y} \mathrm{~S}_{z}$ solid solution," The Journal of Physical Chemistry C, vol. 112, no. 41, pp. 16046-16051, 2008.

[31] M. Fu, Y. Li, S. Wu, P. Lu, J. Liu, and F. Dong, "Sol-gel preparation and enhanced photocatalytic performance of $\mathrm{Cu}$ doped ZnO nanoparticles," Applied Surface Science, vol. 258, no. 4, pp. 1587-1591, 2011.

[32] J. Hu, H. Li, C. Huang, M. Liu, and X. Qiu, "Enhanced photocatalytic activity of $\mathrm{Bi}_{2} \mathrm{O}_{3}$ under visible light irradiation by $\mathrm{Cu}$ (II) clusters modification," Applied Catalysis B: Environmental, vol. 142-143, pp. 598-603, 2013.

[33] G. Colón, M. Maicu, M. C. Hidalgo, and J. A. Navío, "Cu-doped $\mathrm{TiO}_{2}$ systems with improved photocatalytic activity," Applied Catalysis B: Environmental, vol. 67, no. 1-2, pp. 41-51, 2006.

[34] R. Mohan, K. Krishnamoorthy, and S.-J. Kim, "Enhanced photocatalytic activity of $\mathrm{Cu}$-doped $\mathrm{ZnO}$ nanorods," Solid State Communications, vol. 152, no. 5, pp. 375-380, 2012.

[35] G. Q. Li, S. C. Yan, Z. Q. Wang et al., "Synthesis and visible light photocatalytic property of polyhedron-shaped $\mathrm{AgNbO}_{3}$," Dalton Transactions, no. 40, pp. 8519-8524, 2009.

[36] G. Q. Li, "Photocatalytic properties of $\mathrm{NaNbO}_{3}$ and $\mathrm{Na}_{0.6} \mathrm{Ag}_{0.4} \mathrm{NbO}_{3}$ synthesized by polymerized complex method," Materials Chemistry and Physics, vol. 121, no. 1-2, pp. 42-46, 2010.

[37] K.-I. Ishibashi, A. Fujishima, T. Watanabe, and K. Hashimoto, "Quantum yields of active oxidative species formed on $\mathrm{TiO}_{2}$ photocatalyst," Journal of Photochemistry and Photobiology A: Chemistry, vol. 134, no. 1-2, pp. 139-142, 2000. 
[38] G. Q. Li, T. Kako, D. F. Wang, Z. G. Zou, and J. Ye, “Composition dependence of the photophysical and photocatalytic properties of $\left(\mathrm{AgNbO}_{3}\right)_{1-x}\left(\mathrm{NaNbO}_{3}\right)_{x}$ solid solutions," Journal of Solid State Chemistry, vol. 180, no. 10, pp. 2845-2850, 2007.

[39] G. Pecchi, B. Cabrera, A. Buljan, E. J. Delgado, A. L. Gordon, and R. Jimenez, "Catalytic oxidation of soot over alkaline niobates," Journal of Alloys and Compounds, vol. 551, pp. 255-261, 2013.

[40] K. Zhong, J. J. Xue, Y. C. Mao et al., "Facile synthesis of $\mathrm{CuO}$ nanorods with abundant adsorbed oxygen concomitant with high surface oxidation states for CO oxidation," RSC Advances, vol. 2, no. 30, pp. 11520-11528, 2012.

[41] X. B. Li, G. Q. Li, S. J. Wu, X. R. Chen, and W. F. Zhang, "Preparation and photocatalytic properties of platelike $\mathrm{NaNbO}_{3}$ based photocatalysts," Journal of Physics and Chemistry of Solids, vol. 75, no. 4, pp. 491-494, 2014.

[42] G. Li, T. Kako, D. Wang, Z. Zou, and J. Ye, "Synthesis and enhanced photocatalytic activity of $\mathrm{NaNbO}_{3}$ prepared by hydrothermal and polymerized complex methods," Journal of Physics and Chemistry of Solids, vol. 69, no. 10, pp. 2487-2491, 2008.

[43] N. N. Chen, G. Q. Li, and W. F. Zhang, "Effect of synthesis atmosphere on photocatalytic hydrogen production of $\mathrm{NaNbO}_{3}$," Physica B: Condensed Matter, vol. 447, pp. 12-14, 2014.

[44] T. X. Wu, G. M. Liu, J. C. Zhao, H. Hidaka, and N. Serpone, "Photoassisted degradation of dye pollutants. V. Selfphotosensitized oxidative transformation of Rhodamine $\mathrm{B}$ under visible light irradiation in aqueous $\mathrm{TiO}_{2}$ dispersions," Journal of Physical Chemistry B, vol. 102, no. 30, pp. 5845-5851, 1998.

[45] J. C. Zhao, T. X. Wu, K. Q. Wu, K. Oikawa, H. Hidaka, and N. Serpone, "Photoassisted degradation of dye pollutants. 3. Degradation of the cationic dye rhodamine B in aqueous anionic surfactant $/ \mathrm{TiO}_{2}$ dispersions under visible light irradiation: evidence for the need of substrate adsorption on $\mathrm{TiO}_{2}$ particles," Environmental Science and Technology, vol. 32, no. 16, pp. 2394-2400, 1998.

[46] S. Liu, K. Yin, W. Ren, B. Cheng, and J. Yu, "Tandem photocatalytic oxidation of Rhodamine B over surface fluorinated bismuth vanadate crystals," Journal of Materials Chemistry, vol. 22, no. 34, pp. 17759-17767, 2012.

[47] J. Zhuang, W. Dai, Q. Tian et al., "Photocatalytic degradation of $\mathrm{RhB}$ over $\mathrm{TiO}_{2}$ bilayer films: effect of defects and their location," Langmuir, vol. 26, no. 12, pp. 9686-9694, 2010.

[48] G. Q. Li, Z. G. Yi, Y. Bai, W. F. Zhang, and H. T. Zhang, "Anisotropy in photocatalytic oxidization activity of $\mathrm{NaNbO}_{3}$ photocatalyst," Dalton Transactions, vol. 41, no. 34, pp. 1019410198, 2012.

[49] Y. Park, Y. Na, D. Pradhan, B.-K. Min, and Y. Sohn, "Adsorption and UV/Visible photocatalytic performance of BiOI for methyl orange, rhodamine B and methylene blue. Ag and Ti-loading effects," CrystEngComm, vol. 16, no. 15, pp. 3155-3167, 2014.

[50] M. Y. Guo, A. M. C. Ng, F. Liu et al., "Effect of native defects on photocatalytic properties of ZnO," Journal of Physical Chemistry C, vol. 115, no. 22, pp. 11095-11101, 2011.

[51] D. Wang, J. H. Ye, T. Kako, and T. Kimura, "Photophysical and photocatalytic properties of $\mathrm{SrTiO}_{3}$ doped with $\mathrm{Cr}$ cations on different sites," Journal of Physical Chemistry B, vol. 110, no. 32, pp. 15824-15830, 2006. 

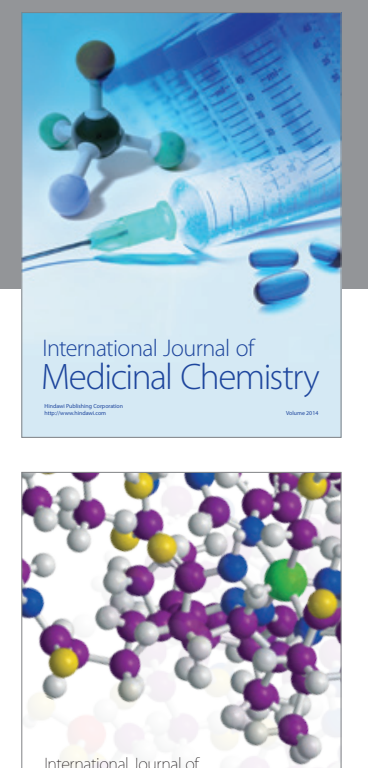

\section{Carbohydrate} Chemistry

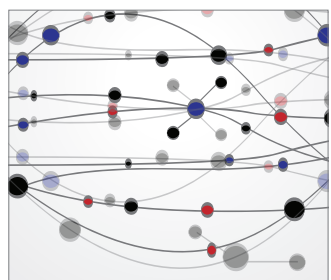

The Scientific World Journal
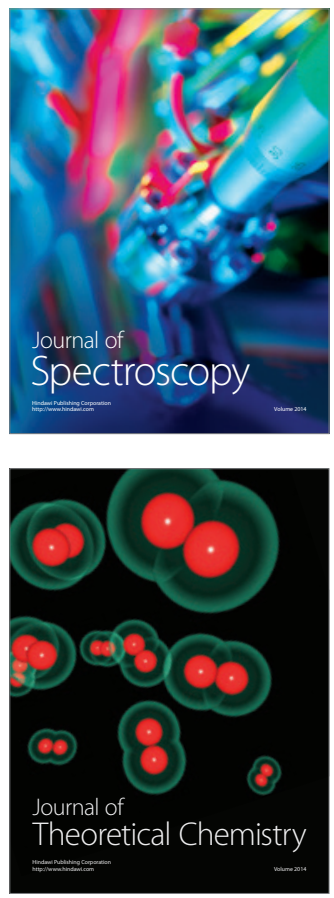
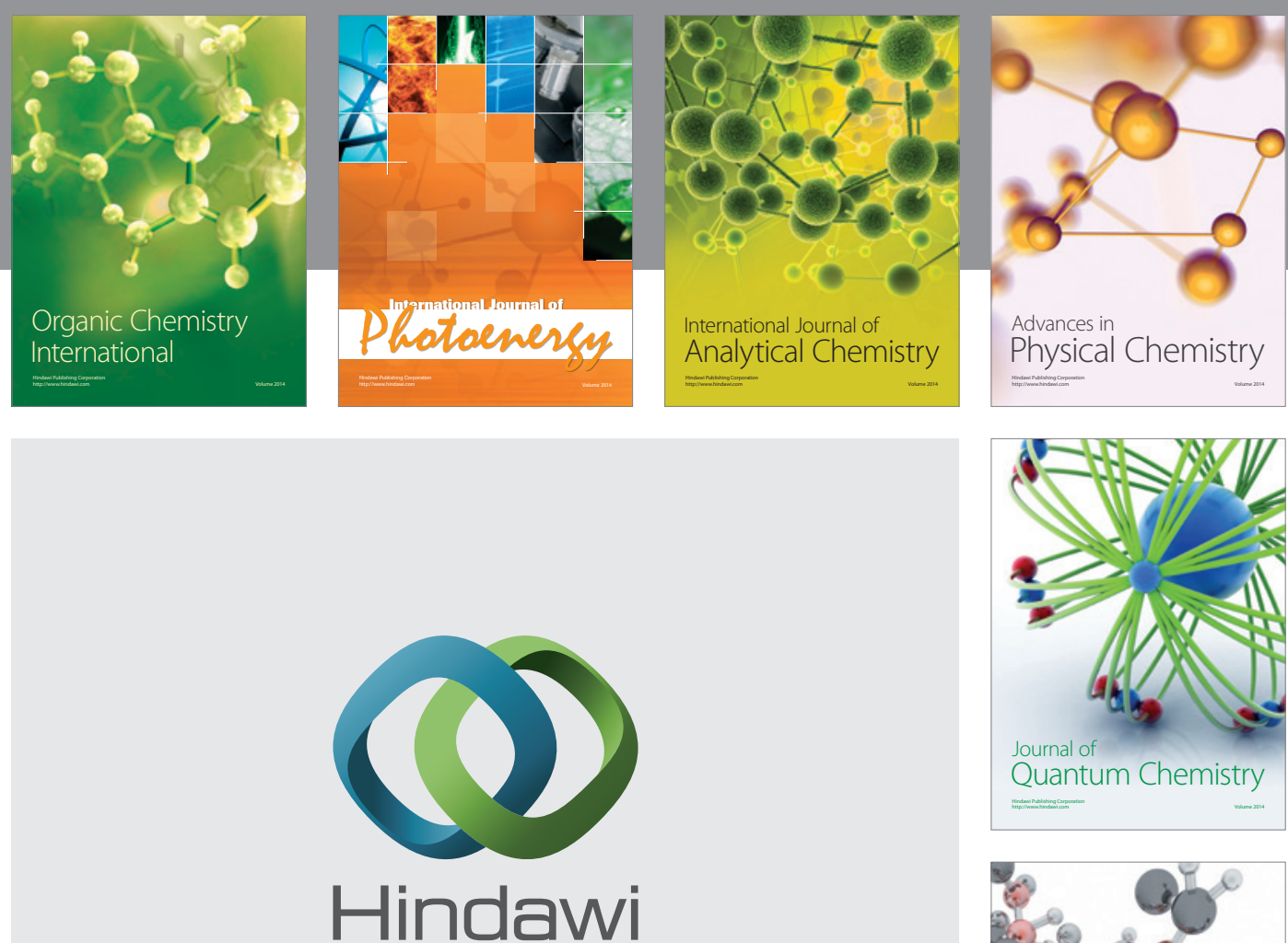

Submit your manuscripts at

http://www.hindawi.com

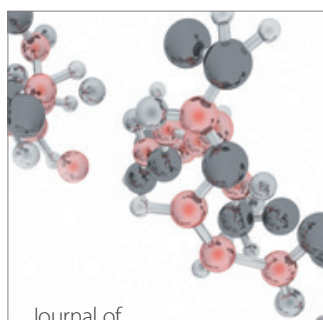

Analytical Methods

in Chemistry

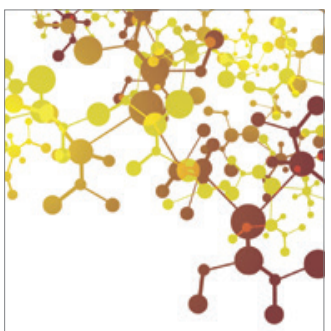

Journal of

Applied Chemistry

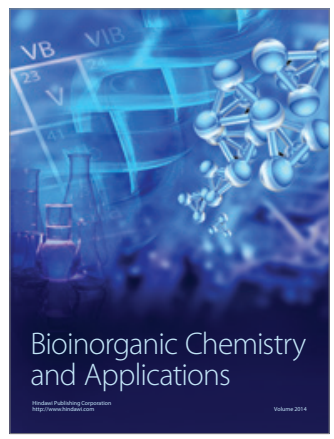

Inorganic Chemistry
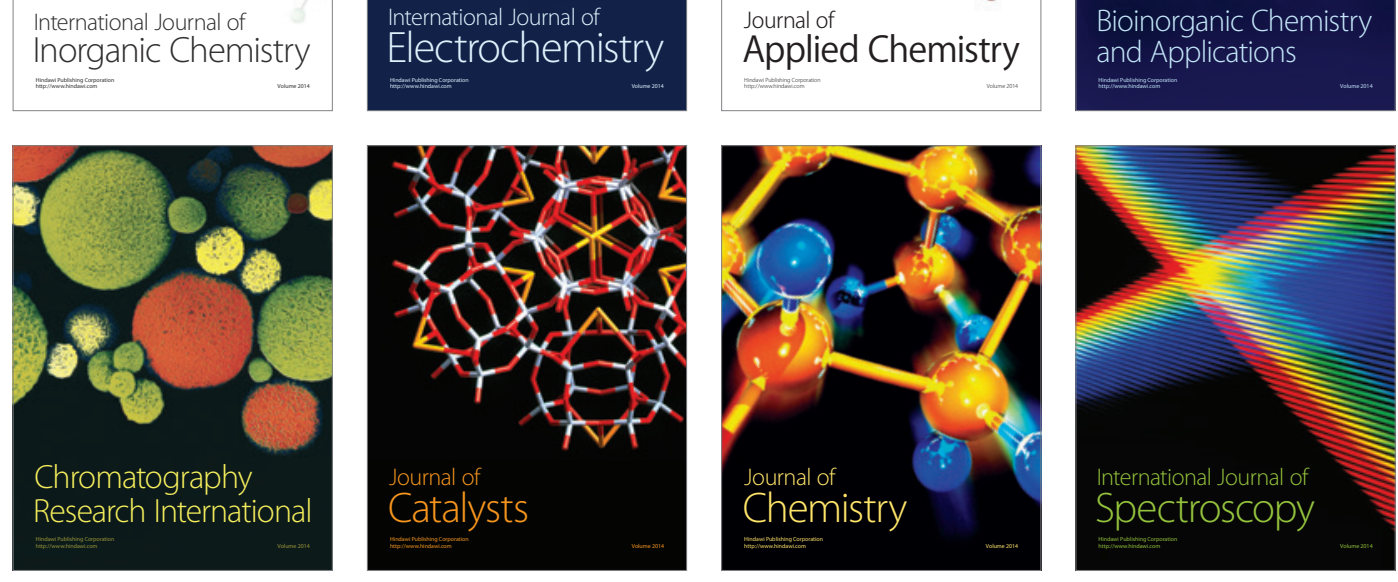